\title{
O discurso sobre as cotas raciais antes da Lei $12.711 / 2012$ : letramentos acadêmicos e a ampliação do acesso ao ensino superior no Brasil
}

\author{
The discourse on racial quotas prior to \\ Law 12.711/2012: academic literacies and \\ the expansion of access to higher education \\ in Brazil
}

\author{
Juliana Silva Santos* \\ *Universidade Federal de Minas Gerais (UFMG), Belo Horizonte, Minas Gerais / Brasil \\ juliana_santos2@yahoo.com.br \\ https://orcid.org/0000-0001-7596-9260
}

\begin{abstract}
RESUMO: Este artigo é de cunho interpretativo e objetiva discutir os letramentos acadêmicos no contexto das políticas de ação afirmativa para a ampliação do acesso ao ensino superior no Brasil. Para tanto, foi feito um percurso que discute os modelos ideológico e autônomo dos letramentos e sobre letramentos e perspectiva cultural, com foco nas populações negra e indígena. Em seguida, foram trazidas questões conceituais sobre os letramentos acadêmicos a partir das considerações de Lea e Street $(1998,2014)$ e sobre a noção de prática institucional do mistério tratada por Lillis (1999) e Lillis e Scott (2007). Para a discussão, foram apresentados dois trechos de artigos de opinião anteriores à aprovação da Lei Federal 12.711/2012 que foram publicados no Boletim, periódico interno à UFMG, com o objetivo de fazer uma correlação entre o discurso da meritocracia utilizado para combater as cotas raciais, as políticas de ação afirmativa e os letramentos acadêmicos.
\end{abstract}

PALAVRAS-CHAVE: letramentos; letramentos acadêmicos; cotas raciais; universidade pública.

ABSTRACT: This article has an interpretative nature and aims to discuss the
academic literacies in the context of affirmative action policies to expand the
access to higher education in Brazil. For such, an overview encompassing the
ideological and the autonomous models of literacies and about literacies
and culture, focusing on black and indigenous populations was conducted.
Following, conceptual issues regarding academic literacies were addressed 
based on the studies of Lea and Street $(1998,2014)$, as well as the notion of the institutional practice of mystery, discussed by Lillis (1999) and Lillis and Scott (2007). Two fragments of opinion articles published prior to Federal Law 12.711/2012 in Boletim, an academic journal of UFMG, were used in this article as a means to correlate the discourse about meritocracy used against racial quotas, affirmative action policies and academic literacies studies.

KEYWORDS: literacy; academic literacies; racial quotas; public university.

\section{Introdução}

A ampliação do acesso ao ensino superior brasileiro por meio de cotas raciais, oficializada por meio da Lei Federal 12.711/2012, ${ }^{1}$ tem favorecido um quadro político-social de inclusão da população negra e indígena em universidades e institutos federais antes nunca visto no país. Ressaltamos o avanço, mas sem desconsiderar o hiato ainda existente entre a presença de negros e indígenas em instituições públicas de ensino superior em relação à população branca.

Conforme dados informados pela Secretaria Especial de Políticas de Promoção da Igualdade Racial (SEPPIR), até 2016 "graças à Lei de Cotas, atualmente, segundo o Ministério da Educação (MEC), 20\% das vagas para estudantes das universidades públicas federais já são ocupadas por pretos, pardos e indígenas" (SANTOS; SOUZA, 2006, p. 46). A informação aponta uma melhoria, principalmente se comparada à quantidade de $1,8 \%$ de pretos e 2,2\% de pardos nas universidades públicas em 1997. Contudo, esses dados também revelam que a paridade entre negros e brancos no ensino superior ainda não é uma realidade. Dessa forma, desde a primeira metade dos anos 2000, as universidades públicas começaram a se deparar com

\footnotetext{
${ }^{1}$ Desde o ano de 2002 iniciaram-se propostas de reserva de vagas de orientação racial em cursos de graduação nos vestibulares de algumas universidades públicas do país. Como exemplo, podemos citar a Universidade Estadual do Rio de Janeiro (UERJ), a Universidade Estadual do Norte Fluminense Darcy Ribeiro (UENF), a Universidade de Brasília (UNB) a Universidade Federal da Bahia (UFBA), entre outras, que adotaram cotas raciais e sociais em seus vestibulares, algumas baseadas em resoluções estaduais e outras em determinações específicas da instituição. A UERJ e a UENF foram as primeiras instituições de ensino superior a propor reserva de vagas para candidatos autodeclarados negros. Para maiores informações ver Lei 3.708/2001. A determinação que garante a reserva de vagas em todas as instituições federais de ensino superior, técnico e tecnológico veio em 2012, com a Lei 12.711.
} 
questões que até então eram abordadas em proporções pouco expressivas em pesquisas do país, como o racismo institucional, o racismo epistêmico e o papel das universidades quanto às demandas de inclusão racial diante das comunidades que as cercam. Por essa razão, a conjuntura social advinda de políticas públicas como a lei de cotas tem fomentado discussões que colocam o ensino superior frente a limites, desafios e possibilidades, convidando as universidades a redimensionar práxis consagradas em sua estrutura, para assim, inserir povos tradicionalmente excluídos da academia e seus respectivos saberes.

A partir desse quadro, é preciso frisar a necessidade de que a atual expansão do ensino superior não passe pela simples inserção de negros e indígenas nas universidades. É imperioso que ocorram modificações internas à práxis universitária, aos currículos e à organização das disciplinas, promovendo um encontro com visões outras, de culturas diferentes e modos de fazer ciência para além daqueles que têm constituído a base epistemológica da produção de conhecimento no ensino superior. Contudo, a relação com aquele que é considerado outro nem sempre se dá de forma tranquila. Isso porque ainda existem discursos que circulam tanto nas universidades quanto fora delas de que o acesso ao ensino superior deve ser voltado para um público capacitado, caracterizando, ainda que de forma camuflada pela organização do discurso, grupos socioeconomicamente privilegiados e majoritariamente brancos. Por essa razão, o ensino universitário brasileiro tem sido colocado em disputa discursiva, pois agora se vê frente a "diferentes maneiras de pensar, atuar, valorizar e falar, que entram em conflito" (ZAVALA, 2010, p. 72).

A partir desse cenário, foi possível identificar olhares catastróficos na grande mídia e em veículos de informação de circulação local quanto ao futuro do ensino superior brasileiro, desde o primeiro momento em que universidades públicas começaram a adotar diferentes modalidades de ações afirmativas em seus processos de admissão. Não raras vezes, circularam discursos que apontavam para uma natural desqualificação de alunos cotistas em relação aos não cotistas frente às exigências acadêmicas e que previam uma possível queda na qualidade do ensino superior público brasileiro após a entrada desses estudantes. É preciso ressaltar, contudo, que a despeito da aparente naturalidade de tais concepções, elas são fruto do histórico de racismo e de discriminação voltados para a população negra e indígena na sociedade, discursos estes que são camuflados pelo mito da democracia 
racial, que começou a tomar fôlego no país a partir da primeira metade do século XX.

Dentre as principais orientações argumentativas ${ }^{2}$ acerca das cotas raciais até o ano de 2012, quando a Lei 12.711 foi aprovada, destacamos a polaridade entre os contrários e os favoráveis à lei de cotas, a miscigenação brasileira, a possível ilegalidade da reserva de vagas e a inadequação dos discentes cotistas em relação à comunidade universitária, tida como letrada na acepção literal do termo. Esta última orientação argumentativa favoreceu a solidificação de discursos que questionam a adoção de ações afirmativas de recorte racial a partir da meritocracia, dada a entrada de alunos que supostamente não teriam adquirido as habilidades necessárias para suprir as demandas de letramentos exigidas pela academia.

Após a aprovação da lei 12.711 em 2012, os discursos sobre as cotas voltaram-se, também, para a identificação de fraudes no sistema e para as avaliações de desempenho dos alunos beneficiados pela política. Nesse sentido, em conformidade com Lillis (2001, p. 19) entendemos que:

Há também resistência fundamental à ampliação do acesso ao ensino superior por alguns grupos, como é evidente nos relatos da imprensa e que se manifestaram na obsessão atual com "qualidade" e "normas". Tal ênfase na qualidade, muitas vezes apenas superficialmente esconde a natureza ideológica dos debates atuais sobre o ensino superior, sobretudo, no que se refere às perspectivas não declaradas sobre quem deve participar, como e com que finalidade. ${ }^{3}$ (Tradução nossa).

Com base no exposto, é possível acrescentar que a visão sobre quem são os sujeitos merecedores de uma vaga no ensino superior é ainda alimentada por um senso-comum de que os aprovados em processos

\footnotetext{
${ }^{2} \mathrm{O}$ tópico que discute os discursos de artigos de opinião contrários à adoção de cotas raciais neste trabalho foi realizado a partir da dissertação intitulada: As cotas raciais em uma publicação jornalística universitária: imagens das relações raciais brasileiras, orientada pela professora Dra. Helcira Lima e defendida em fevereiro de 2016 na Faculdade de Letras da Universidade Federal de Minas Gerais (UFMG).

${ }^{3}$ No original: "There is also fundamental resistance to extending access to higher education from some quarters, as is evident in press reports and which manifested in current obsession with 'quality' and 'standards'. This emphasis on quality often only superficially conceals the ideological nature of current debates about higher education, not least the unstated perspectives on who should participate, how and what end".
} 
seletivos para o ensino superior têm, necessariamente, de dominar por completo elementos referentes ao campo da leitura e da escrita, uma vez que estas habilidades, hipoteticamente, teriam de ter sido adquiridas na vida escolar básica do estudante. Por essa perspectiva, os discentes que porventura não dominem gêneros comuns e cotidianos ao espaço universitário seriam vistos pelo viés da defasagem, discurso este que, para o caso de alunos cotistas, ignora o histórico de exclusão promovido e sustentado no país desde o regime escravista. Ademais, por fazerem uso de uma política pública para os processos seletivos dos vestibulares, esses estudantes seriam tidos como menos aptos ao ensino superior. Contudo, afirma Marinho (2010, p. 366) que,

Torna-se mais coerente esperar e aceitar que os alunos universitários se familiarizem e aprendam a ler e a escrever os gêneros acadêmicos, sobretudo, na instituição e nas esferas do conhecimento em que são constituídos, portanto, quando se inserem nas práticas de escrita universitária.

A partir de Marinho (2010), torna-se possível compreender que os gêneros de produção acadêmica, a exemplo de artigos, teses, dissertações e resenhas acadêmicas não fazem parte do conteúdo normalmente ensinado nas escolas de educação básica, mas sim, nas universidades, dado que são produzidos nessa esfera de circulação. Assim, o interesse desse trabalho, discutir os letramentos acadêmicos no contexto das políticas de ação afirmativa para a ampliação do acesso ao ensino superior no Brasil, é, portanto, decorrente das questões até então apresentadas e terá o seguinte percurso. Em um primeiro momento, apresentaremos concepções de letramento ideológico e autônomo a partir de estudiosos como Soares (1998) e Street $(1984,2007)$. Após essa contextualização teórica, traremos uma discussão sobre questões culturais e letramentos acadêmicos com base em Street (2010) e Lea e Street $(1998,2014)$, seguida de dois trechos de artigos de opinião publicados anos antes da aprovação da lei de cotas no Boletim, periódico de circulação interna à Universidade Federal de Minas Gerais (UFMG). Tais fragmentos foram trazidos a fim de exemplificar uma perspectiva discursiva de insuficiência direcionada ao alunado que seria, no futuro, beneficiário de ações afirmativas.

Com base nos excertos dos artigos de opinião apresentados, que são de perspectiva argumentativa contrária às cotas raciais, fundamentados 
no argumento da meritocracia, objetivamos apontar como a construção discursiva dos locutores deflagra que, anos antes da aprovação da Lei 12.711/12, circulava nos espaços acadêmicos uma concepção que assinalava o déficit de estudantes cotistas quanto às demandas de letramento requeridas pelas universidades. Este quadro, portanto, na visão dos articulistas dos textos selecionados, ocasionaria em consequente queda no nível de ensino das instituições. Também pretendemos gerar reflexões sobre como as universidades, a partir do discurso dos locutores, pareciam seguir um viés do modelo autônomo de letramento (LEA; STREET, 1998, 2014), que privilegia a prática institucional do mistério (LILLIS, 1999; LILLIS; SCOTT, 2007). Como conclusão, apontamos que notadamente após a aprovação da lei de cotas, a adoção de uma perspectiva que considere o modelo dos letramentos acadêmicos se faz de fundamental importância para que as universidades se tornem um espaço mais plural e inclusivo.

\section{Breves considerações sobre os estudos dos letramentos}

A perspectiva sociocultural para os estudos dos letramentos e, posteriormente, dos letramentos acadêmicos foi consolidada no Brasil a partir dos anos 1990 e discutida por estudiosos como Kleiman (1995), Soares (1999), Marinho (2010), Fiad (2011, 2015), entre outros, com foco nos processos de interação entre os sujeitos e com o objetivo de compreender os meios por eles utilizados para se apropriarem da leitura e da escrita em seu contexto social. Por esse caminho, as relações entre ensino e aprendizagem, leitura e escrita seriam dadas a partir de significados baseados no envoltório sociocultural que cerca os sujeitos, tal é a perspectiva pela qual os Novos Estudos dos Letramentos têm sido compreendidos (STREET, 1984; LARSON; MARSH, 2005).

Ao traçar um panorama para os estudos dos letramentos, afirma Soares (1998) que não seria possível considerar uma única definição para o termo, que envolve uma variedade de conhecimentos, habilidades e valores. $\mathrm{Na}$ tentativa de trazer um norte para a diversidade de perspectivas com que os estudos dos letramentos teriam sido abordados, a autora aponta para duas concepções normalmente utilizadas por pesquisadores do campo da educação e da linguística aplicada: uma que considera a dimensão social e outra que considera a dimensão individual dos letramentos. 
O modelo social trata, sobretudo, de buscar compreender o que os sujeitos fazem com as habilidades de leitura e escrita nos contextos em que estão inseridos e como tais habilidades se relacionam com as práticas sociais determinadas. Segundo explica Soares (1998), no campo da dimensão social há ainda duas perspectivas. Uma é a chamada progressista, que defende não haver uma separação entre as habilidades de leitura e escrita em relação aos seus usos. Trata-se de uma visão funcionalista, já que aponta para a necessidade de aquisição de determinadas habilidades específicas por parte dos indivíduos para que possam agir nos espaços sociais. Por essa ótica, o letramento seria responsável por produzir resultados importantes, como o desenvolvimento cognitivo, econômico, profissional e de cidadania (SOARES, 1998). Há ainda uma vertente denominada radical ou revolucionária da perspectiva social. Nesse modelo, a noção de letramentos não é vista como elemento neutro utilizado a partir das exigências de determinadas práticas a que o indivíduo é submetido. Antes, sim, a perspectiva radical entende os letramentos como um conjunto de práticas que envolvem a leitura e a escrita e que reforçam ou questionam as relações de poder existentes. Afirma Soares:

As atividades sociais que envolvem a língua escrita dependem da natureza e estrutura da sociedade e dependem do projeto que cada grupo político pretende implementar, elas variam no tempo e no espaço. Graff $[. .$. afirma que o significado e contribuição do letramento não pode ser pressuposto, ignorando "o papel vital do contexto sócio-histórico" (SOARES, 1998, p. 72).

Ainda na perspectiva tida como radical do letramento social, Kleiman (1995) entende que tal concepção objetiva desencadear em ações que modifiquem a situação de indivíduos marginalizados por não dominarem a escrita dominante. Assim, uma das consequências do modelo social é a de que os estudos dos letramentos já não mais pressuponham efeitos universais de leitura e escrita atrelados à noção de alfabetização e domínio da linguagem. Street $(1984,2007)$ foi um dos pesquisadores voltados para a vertente denominada radical e que colocou em xeque o ensino tradicional da escrita reproduzido, especialmente, nas agências escolares. $O$ autor ampliou a perspectiva do letramento social nomeando-o modelo ideológico, conceito que se opõe ao modelo autônomo dos letramentos, que considera uma dimensão individual. Nas palavras Street (2007, p. 466): 
Prefiro trabalhar com base no que chamo de modelo "ideológico" de letramento, o qual reconhece uma multiplicidade de letramentos; que o significado e os usos das práticas de letramento estão relacionados com contextos culturais específicos; e que essas práticas estão sempre associadas com relações de poder e ideologia: não são simplesmente tecnologias neutras.

O modelo ideológico como uma prática de letramento, portanto, se ocupa de atividades socialmente situadas de uso da escrita, sem ignorar as relações de poder que as permeiam. Nesse modelo, a leitura e a escrita não são pautadas como a aquisição de uma habilidade técnica que pode ser transmitida. Logo, entende-se que não basta ensiná-las como elementos a serem decodificados de forma instrumentalizada. Antes sim, importa oferecer aos sujeitos oportunidades para compreender as situações sociais de interação mediadas pelo texto. Com essa definição, Street (2007) assinala que as práticas sociais de leitura e escrita que compõem a noção de letramento possuem significados político-ideológicos que devem ser encarados pelos sentidos que tais práticas assumem nos diversos contextos (SOARES, 1998). Mais ainda, a perspectiva do letramento ideológico não busca delimitar a escola como única agência de letramento para que o indivíduo se envolva em práticas de leitura e escrita. Pelo contrário, a vertente ideológica entende que os vários entornos sociais em que o sujeito se insere também devem ser considerados campos possíveis para o desenvolvimento de práticas de letramento. Assim, o trabalho, a família, instituições religiosas, entre outros espaços são também considerados meios capazes fomentar práticas de letramento.

Se analisada por uma visão diacrônica, a perspectiva trazida por Street $(1984,2007)$ pode ser considerada de aplicação recente nos espaços de ensino. Ao longo da história, é possível notar que o ensino escolar tem focado em uma perspectiva de letramento que entende leitura e escrita como códigos a serem decifrados, privilegiando um modelo individual. Concepções desse tipo têm se sustentado no que Street (1984, 2007) denominou como modelo autônomo, ou seja, um conjunto de competências tidas como ideologicamente neutras e que comportam habilidades cognitivas e universais que se voltam para a leitura e a escrita em geral. Nesse modelo, tais habilidades são tidas como independentes de fatores sociais, não interessando os contextos em que se o sujeito esteve envolvido ao longo de sua vida. A escola, nesse caso, é encarada como única 
agência de letramento possível, o que torna iletrados quaisquer indivíduos que não tenham tido acesso a um determinado modelo dominante e escolar. Segundo Street (1984, p. 20), os autores partidários do modelo autônomo advogam ainda que "membros de sociedades letradas têm a possibilidade de desenvolver funções lógicas, de se especializar nas 'funções reais' da linguagem". Nesse sentido, é possível depreender que sociedades tidas como letradas ou que se apropriaram da cultura escrita seriam, consequentemente, mais desenvolvidas do que as comunidades de cultura oral ou de classes economicamente desfavorecidas.

Como será abordado com maiores detalhes no decorrer deste texto, os estudos sobre os letramentos acadêmicos, grosso modo, buscam analisar as formas utilizadas para a construção de conhecimento de estudantes universitários, notadamente aqueles advindos de minorias sociais e com histórico de discriminação (LEA; STREET, 1998, 2014). Dessa forma, entende-se que o modelo dos letramentos acadêmicos tem forte influência da perspectiva ideológica desenvolvida nos Novos Estudos do Letramento, dado que na concepção dos letramentos acadêmicos "qualquer texto, ferramenta, tecnologia ou prática social pode tomar significados (e valores) bem diferentes em diferentes contextos" (GEE, 1996, p. 188). Por consequência, quando ausentes de contexto, tais ferramentas deixam de ter significados. Nesse sentido, cabe ainda trazer dois conceitos importantes, que são as noções de eventos de letramento e de práticas de letramento.

Em linhas gerais, os eventos de letramento seriam os "elementos mais observáveis das atividades que envolvem a leitura e a escrita" (STREET; CASTANHEIRA, 2014, p. 258-259) e que tenham o texto escrito como elemento central, mesmo que este não esteja materialmente presente, mas seja o conteúdo da interação. Já a concepção de práticas de letramento, de acordo com Street e Castanheira (2014, p. 259):

Distancia-se do contexto imediato em que os eventos ocorrem, para situá-los e interpretá-los em contextos institucionais e culturais a partir dos quais os participantes atribuem significados à escrita e à leitura, e aos eventos de que participam.

Nesse sentido, é possível complementar com Barton e Hamilton (1998), que a noção de práticas de letramento se configura como não observável por compreender sentimentos, valores, conhecimentos partilhados, sentidos e regras das relações sociais. Tais conceitos tornam- 
se ainda mais claros no contexto teórico que envolve os letramentos acadêmicos, por darem relevância a diferentes formas de interação com a leitura e a escrita em diferentes contextos sociais. Mais ainda, afirmam Street e Castanheira (2014) que a utilização dos conceitos de eventos e de práticas, no plural, ressalta o valor social dos usos da escrita, que é variável de um grupo social para outro e que se configura como objeto de disputa em relações econômicas, religiosas e políticas. É por esse viés que aproximamos a discussão dos letramentos e dos letramentos acadêmicos ao contexto de implementação da política de cotas raciais em instituições de ensino superior. A entrada na universidade de grupos sistematicamente marginalizados de espaços consagrados para a produção do conhecimento implica pôr em prática o entendimento de que ser letrado é o resultado de aprendizados que são de ordem não apenas epistemológica e individual, mas também de trajetórias, culturas e das identidades. Nesse sentido, acirramse no cotidiano acadêmico disputas de concepções sobre o que seria uma boa ou má universidade, um bom ou um mau estudante, bem como quais seriam as culturas desejáveis ou não para o ensino superior. O contexto atual vivido pelas universidades brasileiras, portanto, pode tanto se configurar em possibilidades de diálogo, de negociação e de encontros culturais, quanto em um campo de assimetrias, choques e manutenção unidirecional de poder.

\subsection{Conexões entre letramentos, culturas e ações afirmativas}

No que diz respeito às culturas e práticas de letramento, Street (2007) correlaciona as noções de letramento e de identidade, partindo do pressuposto de que as práticas de letramento constituem a identidade, a subjetividade. Nas palavras do autor:

Quando frequentamos um curso ou uma escola, ou nos envolvemos num novo quadro institucional de práticas de letramento, por meio do trabalho, do ativismo político, dos relacionamentos pessoais etc., estamos fazendo mais do que simplesmente decodificar um manuscrito, produzir ensaios ou escrever com boa letra: estamos assumindo - ou recusando as identidades associadas a essas práticas (STREET, 2007, p. 470).

A partir dessa percepção, é possível entender com Street (2007) que identidade e letramento devem ser interpretados nas particularidades culturais, ou seja, o que faz parte de uma perspectiva dominante em uma determinada sociedade pode não o ser em outras. Ademais, o letramento 
tido como de prestígio tende a marginalizar outras variedades, especialmente ao afirmar essa dominação nos quesitos de classe, cultura, e acrescentamos nesse trabalho, de raça. Nas palavras do autor:

O fato de uma forma cultural ser dominante é, no mais das vezes, disfarçado por trás de discursos públicos de neutralidade e tecnologia nos quais o letramento dominante é apresentado como o único letramento. Quando outros letramentos são reconhecidos, como, por exemplo, nas práticas de letramento associadas a crianças pequenas ou a diferentes classes ou grupos étnicos, eles são apresentados como inadequados ou tentativas falhas de alcançar o letramento próprio da cultura dominante: exige-se então a atenção remediadora, e os que praticam esses letramentos alternativos são concebidos como culturalmente desprovidos. Dentro do campo da linguística já se reconheceu claramente que existe uma grande variedade de formas de língua - dialetos, registros, crioulos etc. - e que o padrão é, ele também, apenas mais uma "variedade". O modo como um padrão alcança esse status foi posteriormente enfatizado pela cunhagem da expressão língua dominante [...], que deixa explícito que se trata de poder e de luta pela dominação, mais do que de um processo natural da emergência do "melhor" como padrão (STREET, 2007, p. 472).

A questão trazida pelo autor é de suma importância, principalmente, se correlacionada à possibilidade de reconhecimento de culturas e saberes advindos de povos negros e indígenas que chegam às universidades. É preciso explicar, contudo, que chamamos de chegada à universidade a inclusão desses grupos por meio de políticas públicas de ação afirmativa, dado que historicamente tais povos sempre tiveram limitados ou mesmo negados o acesso à educação. Conforme aponta Santos (2016, p. 141), dados do Ministério da Educação afirmam que

Ainda no século XIX, permaneciam legislações que excluíam os negros do acesso à educação, como o Decreto de Lei no 1.331 , de 17 de fevereiro de 1854, que estabelecia a não admissão de escravizados nas escolas públicas do país e que a instrução para adultos negros dependeria da disponibilidade de professores.

Nesse sentido, Souza (2009) esclarece que tal perspectiva permaneceu mesmo nas primeiras décadas do século XX. Nas palavras da autora, 
Ainda que o distanciamento da escola fosse motivado por questões objetivas, como a necessidade de trabalhar, algumas famílias tiravam, ou nem chegavam a matricular seus filhos, diante da impossibilidade de atender às exigências que, conforme documentos escolares da época, incluíam vestimentas adequadas; presença de um adulto responsável para realizar matrícula; além de necessidades de adquirir material escolar e merenda. Esses requisitos se não atendidos, resultavam em constrangimentos e abandonos [...]. Conforme registrado em relatórios da Instrução Pública de São Paulo, havia receios em aceitar matrículas de crianças negras na escola, dado o medo das famílias brancas que poderiam recusar-se a manter seus filhos nas instituições, receosas da proximidade com esses sujeitos abjetos socialmente à época (SOUZA, 2009, p. 35-36).

A partir das ilustrações trazidas pelas autoras é possível perceber que ao longo da história brasileira a população negra tem sido privada das perspectivas dominantes de letramento, o que permite concluir que as instituições de ensino poderiam ter sido elaboradas como espaços mais diversamente ricos, caso a presença desses sujeitos tivesse sido feita de forma inclusiva. Para exemplificar, a incorporação do ensino de cultura e história afro-brasileira e indígena ao currículo da educação básica foi instituída somente em 2003, a partir das Leis 10.639/2003 e 11.645/2008. Contudo, ainda assim, é possível encontrar escolas que não aplicam tais legislações e que permanecem silenciando as contribuições desses povos na construção material e cultural da nação, às vezes chegando ao ponto de associar as práticas de letramento comuns a esses grupos a elementos exóticos ou folclóricos, restritos a datas específicas, ou nos dizeres de Street (2007, p. 472) "apresentados como inadequados ou tentativas falhas de alcançar o letramento próprio da cultura dominante". Este é o caso quando a característica oral das comunidades africanas é tida como menor em comparação ao caráter substancialmente mediado pela escrita das comunidades europeias, ou quando há proibição, seja por parte de gestores escolares ou mesmo de genitores do alunado, de se compreender no espaço escolar o funcionamento das religiões de matriz africana. Tais concepções, contudo, normalmente não são ditas explicitamente, mas são difundidas no interdiscurso de currículos ocultos que transmitem valores e crenças que subjazem às rotinas e às relações sociais nas instituições de ensino e na sociedade, por consequência. Nesse sentido, entendemos que os modos culturais de se tratar a escrita, seja na educação básica ou superior, 
permanecerão como um campo de conflitos enquanto persistirem valores e ideologias que têm na cultura branca europeia um modelo de normatividade. Assim, é possível concluir com Gomes que,

Cabe ao educador e à educadora compreender como os diferentes povos, ao longo da história, classificaram a si mesmos e aos outros, como certas classificações foram hierarquizadas no contexto do racismo e como este fenômeno interfere na construção da autoestima e impede a construção de uma escola democrática. É também tarefa do educador e da educadora entender o conjunto de representações sobre o negro existente na sociedade e na escola, e enfatizar as representações positivas construídas politicamente pelos movimentos negros e pela comunidade negra. A discussão sobre a cultura negra poderá nos ajudar nessa tarefa (GOMES, 2003, p. 77).

Afina-se com essa noção a perspectiva de Street (2003, p. 77): “a abordagem autônoma está simplesmente impondo as concepções ocidentais de letramento a outras culturas ou, dentro de um mesmo país, as concepções de uma classe, ou grupo social, aos demais". Entendemos, portanto, que uma vez que as políticas de ação afirmativa para a educação superior são um dos meios de romper com as assimetrias a que os povos negros e indígenas estiveram submetidos ao longo da história, a inclusão dos saberes desses grupos nos espaços universitários faculta o entendimento de que a noção de letramento é variável segundo o contexto e a cultura em que é desenvolvida.

\section{Os letramentos acadêmicos e as políticas de ação afirmativa como possibilidades de ampliação do acesso e da permanência no ensino superior}

Como já sinalizamos, uma perspectiva dos letramentos acadêmicos deve conceber a leitura e a escrita como práticas sociais variáveis, segundo elementos como contexto e cultura (LEA; STREET, 1998, 2014; STREET, 2003), apontando para novas formas de compreender, interpretar e, sobretudo, incluir o conhecimento de estudantes no ensino superior. Por serem socialmente situados, é possível considerar com Fiad que os letramentos acadêmicos dizem respeito a práticas específicas do espaço universitário devido à circulação de gêneros e demandas relativas a esse meio: 
Assume-se que há usos específicos da escrita no contexto acadêmico, usos que diferem de outros contextos, inclusive de outros contextos de ensino. Embora alguns estudiosos entendam o conceito de letramento acadêmico compreendendo todo contexto onde há práticas formais de escolarização [...], prefiro considerar letramento acadêmico como restrito ao contexto universitário, embora saiba que há práticas de letramento comuns a todos os contextos escolares, sejam da educação básica até a universidade (FIAD, 2011, p. 362).

Dessa forma, no contexto dos Novos Estudos do Letramento, que se ocupam de investigar práticas sociais mediadas pela escrita, Lea e Street (1998, 2014), assim como Barton (1994), Gee (1996), Lillis (1999, 2001), Fiad (2011, 2015), vão tratar dos chamados letramentos acadêmicos com base em concepções que vão além da compreensão do código linguístico em si, mas como prática social inserida em contextos institucionais e disciplinares determinados (STREET, 2010). Em linhas gerais, os letramentos acadêmicos buscam analisar os meios utilizados para a construção de práticas de leitura e de escrita de estudantes universitários. Por via de regra, as pesquisas do campo direcionam a atenção a grupos estudantis advindos de minorias sociais e com histórico de discriminação, desafiando a lógica dominante de déficit. Mais ainda, esse modelo busca o desenvolvimento de práticas e comportamentos sociais mediados pela leitura e pela escrita, focalizando "as relações entre poder, autoridade, produção de sentido e identidade, implícitas às práticas de letramento em quadro institucional específico" (LEA; STREET, 2014, p. 481). Nessa perspectiva, os saberes de um discente advindo de contextos estigmatizados de uma determinada sociedade não devem ser invalidados para que ele se insira em uma "cultura adequada", tampouco esse aluno deve ser considerado iletrado. Assim, ao associarmos o modelo dos letramentos acadêmicos às políticas de ação afirmativa para o ingresso no ensino superior, é necessário frisar que:

Uma instituição, que se disponha a implantar plano de ações afirmativas para a população negra, não pode encará-lo como "proteção a desvalidos", segundo pretendem alguns. É preciso que um plano com tais metas incentive a compreensão dos valores da diversidade social, cultural, racial e, nestes valores, busque apoio para orientar suas ações educativa, de formação de profissionais e de responsável pelo avanço das ciências. Sem dúvida, a universidade, ao prever e executar medidas visando à inclusão de grupos até então deixados à margem, inclui-se na sociedade, passa a dela fazer parte e assume compromisso com ela, já 
que deixa de atender unicamente aos interesses de um único segmento até então privilegiado (SILVA, 2003, p. 48).

A perspectiva da autora traz, então, a necessidade de se considerar e entender os modelos de letramento a que o estudante em questão foi exposto ao longo de seu percurso educativo, para que a universidade seja um espaço mais plural e desfocada de um modelo autônomo de letramento. Assim, o estudo sobre os letramentos acadêmicos realizado por Lea e Street (1998, 2014), considerado um marco que consolida as pesquisas nesse campo, apresenta três modelos de abordagem da produção textual dos discentes em contexto universitário, assim denominadas:

a) o estudo das formas linguísticas, que traz o foco para habilidades de ordem cognitiva e aspectos superficiais do texto. O estudante é visto a partir do déficit dado que o texto escrito é posto como reflexo das habilidades de uso da língua;

b) o modelo da socialização acadêmica, que parte da premissa de que os discentes devem ser aculturados no que diz respeito aos discursos e gêneros propostos nas disciplinas. Nesse modelo, o professor é o sujeito responsável pela inserção do aluno na cultura universitária;

c) o modelo dos letramentos acadêmicos, que apresenta foco nas construções de sentido, de poder, autoridade e de identidade e que traz um olhar para os letramentos a partir de questões epistemológicas mais aprofundadas (LEA; STREET, 2014; STREET, 2010).

Segundo Sito (2016), entre os objetivos dos estudos do letramentos acadêmicos estão a aproximação das perspectivas dos escritores-estudantes, o reconhecimento das formas que as convenções da escrita acadêmica incidem sobre a construção do conhecimento a partir da voz dos discentes e a busca por compreender se na academia são construídas alternativas para a construção do conhecimento e quais alternativas seriam essas.

A emergência dos estudos dos letramentos acadêmicos se deu com a expansão do acesso à universidade nos anos 1990, na Grã-Bretanha, momento em que as discussões sobre o conceito social de letramento também começavam a ganhar corpo. Nesse contexto, Street (2010) informa que o período de internacionalização do ensino superior na Inglaterra fez emergir questionamentos sobre a participação de estudantes estrangeiros nas universidades e as práticas comunicativas promovidas nas instituições. 
Este foi um momento em que se discutiu sobre uma possível "crise" no ensino superior inglês, o que fez aflorar os estudos dos letramentos com foco na academia. Tal contexto se deu em resposta aos discursos de insuficiência atrelados à expansão do ensino superior pela inserção de estudantes advindos de minorias linguísticas. Assim, afirmam Lea e Street (2014, p. 491) que "em vez de destacar os déficits dos alunos, a abordagem do modelo de letramentos acadêmicos coloca em primeiro plano a variedade e a especificidade das práticas institucionais e a luta dos estudantes para que essas práticas façam sentido". As produções teóricas desse momento, então, estiveram voltadas para a elaboração de cursos de escrita para estudantes, bem como para o reconhecimento dos conflitos vivenciados por eles quando da sua inserção nas universidades.

A partir do exposto e como já apontamos anteriormente, entendemos que não só as universidades inglesas, mas também as brasileiras em momentos mais recentes, têm passado por transformações, que no Brasil, foram iniciadas por políticas públicas de acesso ao ensino superior como as políticas de ações afirmativas de recorte racial, o que têm colocado as instituições de ensino superior ainda mais diretamente como objeto de análise acadêmica. Ademais, tais espaços de educação têm sido chamados a se envolver no contexto de diversidade cultural e racial que os cercam, impulsionados pela voz de sujeitos interessados em ampliar e descolonizar o conhecimento, provocando reflexões sobre o papel social das universidades brasileiras. Assim, a partir de uma perspectiva ideológica dos letramentos e dos letramentos acadêmicos, entendemos a necessidade de se considerar um olhar pós-colonial para os saberes de forma a questionar moldes historicamente excludentes. Uma perspectiva dos letramentos acadêmicos, portanto, torna possível compreender como e para que a escrita é utilizada no contexto universitário e quais são suas implicações para o estabelecimento de relações de poder e das identidades. Nesse aspecto, Lillis e Scott (2007) afirmam que o modelo dos letramentos acadêmicos questiona o imaginário de homogeneidade dos discentes, da estabilidade das disciplinas e da relação unidirecional entre professor e estudante.

Ao voltarmos o nosso foco de forma mais específica para a escrita acadêmica, Lillis (1999) pesquisou o que foi por ela denominado de "prática institucional do mistério”. De acordo com a autora, as práxis que compõem a escrita acadêmica fariam parte de um determinado senso-comum que as tornariam naturais para os discentes. Por essa lógica, é possível depreender 
que aqueles sujeitos considerados "de fora" ou não homogêneos, seriam tidos como inaptos à universidade e sua cultura. A concepção de prática institucional do mistério, portanto, se alinha ao modelo autônomo de letramento, reforçando a perspectiva de déficit, por frisar a perspectiva de que convenções de leitura e escrita são tidas como autônomas e naturalmente identificáveis. Segundo Franco e Castanheira (2016, p. 16), "tal prática consolida-se quando não são explicitadas ao aluno as convenções que regem a escrita acadêmica e quando o professor pressupõe que o discente já as saiba". Fiad (2011) elucida ainda mais as considerações de Lillis (1999), ao apontar para a necessidade de se esclarecer não só o gênero acadêmico, mas também as razões para o uso de tais gêneros na academia:

É preciso mais: precisam ficar claros os motivos pelos quais algumas práticas são privilegiadas no domínio acadêmico em detrimento de outras, qual significado determinada prática de letramento tem nesse domínio, o que significa justificar e argumentar de acordo com as convenções escriturais da academia, entre outros fatores (FIAD, 2011, p. 363).

A prática institucional do mistério seria, por isso, avessa às propostas de universidade na contemporaneidade, por negar as identidades do aluno real, diverso de culturas, locais de origem e trajetórias.

\section{O discurso da meritocracia e o modelo dos letramentos acadêmicos: novas possibilidades para a universidade contemporânea}

Nos dez anos anteriores à Lei 12.711/2012 em que as cotas raciais estiveram em debate no país, uma das orientações argumentativas contrárias à implementação da lei e que obteve grande adesão da população inserida ou não em meios acadêmicos foi a questão da meritocracia. Em linhas gerais, a defesa do mérito individual e acadêmico corresponde a um princípio liberal de seleção dos mais aptos e tem origem na Europa entre os séculos XVII e XIX. Parte-se do pressuposto de que cada indivíduo possui capacidades e oportunidades iguais para a competição em diversos espaços sociais dentre eles, a universidade. Por essa perspectiva, a proposição de cotas seria tida como uma afronta ao princípio constitucional da isonomia, além de colocar em xeque a excelência das universidades públicas brasileiras, dado que estas passariam a receber alunos menos aptos ao desenvolvimento intelectual em 
seu meio. $\mathrm{O}$ argumento da meritocracia, portanto, não assimila diferenças produzidas socialmente, como raça, gênero, classe social ou região. Nesse sentido, é possível compreender que a defesa da meritocracia como escudo para refutar as cotas raciais nas universidades seguiria o modelo dominante que advoga o déficit de determinados grupos de alunos, pois entende que determinadas habilidades, como as de leitura e de escrita, já devam fazer parte de um conhecimento geral e previamente adquirido.

Dessa forma, o sujeito que de alguma forma não tenha participado de contextos sociais que propiciem o desenvolvimento de gêneros privilegiados em meio acadêmico seria visto como um problema para a universidade e, portanto, inapto. Vejamos exemplos nesse sentido. Os trechos dos artigos de opinião a seguir são de um periódico semanal intitulado Boletim, produzido pela Diretoria de Divulgação e Comunicação Social da Universidade Federal de Minas Gerais (UFMG) e foram retirados de uma versão on-line. Criado no ano de 1974 e de distribuição gratuita nas unidades da instituição, o Boletim publica notícias, entrevistas e outros gêneros jornalísticos que privilegiam temáticas relacionadas ao cotidiano acadêmico e científico, além de atividades importantes promovidas pela UFMG. O público leitor é formado, majoritariamente, por estudantes de graduação, pós-graduação, docentes e funcionários da administração. Os textos selecionados para nossa análise são da seção "Opinião", 4 que publica artigos de opinião de autoria da comunidade acadêmica e também de fora dela sobre assuntos variados e condizentes com a agenda atual de debates do país. No que diz respeito à temática das cotas raciais, expressiva parcela dos artigos foram de autoria de professores e membros da própria Universidade.

Quanto ao método de escolha dos textos, os dois trechos analisados são de artigos publicados entre os anos de 2002 e 2012, ou seja, estão entre os dez anos de debates sobre as cotas raciais em universidades públicas do país, desde as primeiras iniciativas até a aprovação da Lei 12.711/2012. ${ }^{5}$

\footnotetext{
${ }^{4}$ Em nota de rodapé da seção "Opinião", a Universidade esclarece que as opiniões expressas nos textos são de responsabilidade exclusiva dos autores.

${ }^{5}$ Os exemplos trazidos nessa seção foram discutidos pelo viés da análise do discurso na dissertação de Santos (2016) intitulada As cotas raciais em uma publicação jornalística universitária: imagens das relações raciais brasileiras, que apresenta uma quantidade maior de textos analisados. Para o desenvolvimento da dissertação, foram encontrados 42 textos, 30 deles com referência direta às cotas raciais ou outra forma de Ação
} 
Para a seleção das publicações em discussão nesse trabalho, foram aplicadas palavras-chave como "cotas, cotas raciais, cotas sociais, ações afirmativas e reforma universitária” a cada um dos artigos publicados no período indicado e que apresentaram as ações afirmativas como temática. Nesse trabalho, é nosso objetivo dar atenção a elementos de ordem linguístico-discursiva na construção textual dos locutores em questão e que argumentaram de forma contrária às cotas raciais pelo viés da meritocracia, antes da aprovação da lei $12.711 / 2012$ :

Característico fenômeno de decadência cultural é o achatamento de valores. Característico e perverso, pois o que, segundo a boa razão, antes exprime uma perda que um ganho, passa a se ver assimilado ao avanço e ao progresso. O ethos que, de um lado, conferia rosto e identidade às instituições e, de outro, demarcava no imaginário coletivo o bom e o ruim, dilui-se [...]. Ora, onde tudo se parece, não há espaço para a excelência [...]. Na milenar tradição cultural do Ocidente e do Oriente, a universidade sempre foi percebida como o lugar ímpar de aplicação às formas superiores do saber [...]. Alguns fenômenos sugerem que esteja ocorrendo o contrário. Catastrofismo? Antes fosse. Um exemplo é a ideia de cotas para grupos étnicos ou para desfavorecidos de qualquer outro matiz. Criar distinções fundadas na etnia ou em condições sociais e econômicas é um modo cínico e arrogante de legitimar preconceitos, porque perpetua a inferioridade do desvalido. Ao se afastar do princípio do mérito para se pôr a serviço do imediato nivelamento social, a universidade começa por trabalhar contra a principal de suas forças, que é precisamente o dinamismo transformador do saber. Nega-se a si própria. Rompe com suas origens. Trai o seu destino [...]. Há muito, de resto, se percebeu, em ambientes menos festivos, que a universalização indiscriminada do ensino universitário, mesmo sem o sistema de cotas, ao invés de criar uma sociedade universalmente elitária, conduz ao que a crítica da pedagogia fácil chamou de akademisches Proletariat: um dos bons roteiros para o desemprego e a indigência [...]. O simples fato de que fenômenos como esses - cotas para afrodescendentes ou egressos do ensino público, dispensa de revalidação de estudos feitos em Cuba, atribuição de diploma a perseguidos políticos - tenham amplo assento na mídia e constituam objeto de importantes fóruns de

\footnotetext{
Afirmativa. Por ser um material muito extenso, foi feita uma seleção daqueles que discutiam a temática das cotas raciais de forma ainda mais direta, o que fez com que o corpus final da pesquisa tivesse um total de 14 artigos de opinião: sete de orientação argumentativa favorável à política e sete de orientação argumentativa contrária a ela.
} 
discussão, é sintomático. Revelam o quanto de desapreço votamos à nossa universidade. E, em outra vertente, como é chinfrim o respeito que nutrimos pela Constituição da República, cujo art. 206, VII, faz da qualidade uma garantia do ensino sob todas as formas e em todos os níveis. (UNIVERSIDADE FEDERAL..., 2005, p. 2).

No exemplo destacado, a seleção lexical de expressões como "decadência cultural", "achatamento de valores", "perverso", entre outras, demonstra a posição do locutor sobre a política de cotas e seu público-alvo, além de implicar os leitores sobre a nocividade das ações afirmativas de recorte racial. Os candidatos negros e indígenas, alvo da política, são vistos a partir da lógica do déficit, o que os torna indesejáveis ao espaço acadêmico. Segundo o olhar do locutor, há uma "decadência cultural" que advém do "achatamento de valores", valores estes que não estariam sendo levados em conta com a proposição da política em questão. No decorrer do trecho em destaque, há também uma percepção de que mérito acadêmico e inserção social são dois elementos completamente díspares. Isso porque o chamado o "nivelamento social imediato", utilizado como sinônimo de cotas raciais, fez com que a proposição de cotas perca o seu lugar de política pública para ser atrelada ao imediatismo e à irreflexão, prática comumente contrária aos valores socialmente partilhados pelo espaço universitário.

Além dos argumentos deflagrados pela seleção lexical, o trecho em questão, ao defender o princípio meritocrático de que o indivíduo é o único responsável pelo sucesso ou insucesso de sua trajetória, traz implícito outras questões que merecem destaque. A primeira delas é a alegação de que o desempenho acadêmico é resultado de habilidades individuais, reforçando dicotomias como alfabetizados $\mathrm{X}$ analfabetos, letrados $\mathrm{X}$ iletrados, aptos X não-aptos (FIAD, 2011). Por esse viés, é possível depreender uma forte influência de um modelo autônomo dos letramentos (STREET, 1984), que concebe a aquisição de estratégias de letramento e as práticas de leitura e escrita como um produto finalizado em si mesmo e ausente de qualquer contexto social. Outro elemento que sugerimos destaque é o reforço da prática institucional do mistério (LILLIS, 1999). Conforme apresentado, a argumentação do articulista defende um modelo tradicional de universidade ao sustentar que a inserção de alunos cotistas causaria um "achatamento de valores", em que as noções de "bom e o ruim" se perderiam. Por essa perspectiva, é possível perceber uma crença de que estudantes não cotistas chegariam à universidade prontos para atender as demandas de letramento 
do cotidiano universitário, situação que não se aplicaria a estudantes cotistas. Nas palavras de Lillis:

Embora prevaleça a visão de que tais convenções [sobre a escrita acadêmica na universidade] não são problemáticas e são simplesmente "senso comum", eu defendo que a confusão é uma dimensão tão difundida em toda a sua experiência como grupo de estudantes "não tradicionais" no ensino superior que aponta para uma prática institucional de mistério ${ }^{6}$ (LILLIS, 1999, p. 131).

Já o exemplo apontado a seguir apresenta a mesma orientação argumentativa ao defender o imaginário de que as cotas raciais colocariam em xeque a excelência acadêmica:

As cotas, por mais que sejam bem-intencionadas na busca da equidade social, acabam por desestruturar a única baliza de qualquer sistema de ensino: o mérito. A única forma de efetividade social que, a nosso ver, toca a uma universidade é a de ensinar muito bem, pesquisar excelentemente e estender o seu conhecimento à sociedade. Fazendo bem essas três funções, cuja baliza é o mérito acadêmico, a universidade cumprirá a sua função de aprimorar a sociedade e o país. Abdicar dessas funções específicas é tornar o seu papel inócuo. [...] Cotas apenas trocam o perfil dos ingressos à custa da excelência acadêmica (UNIVERSIDADE FEDERAL..., 2006, p. 4).

Nesse trecho, o locutor caracteriza as cotas como "bem-intencionadas na busca da equidade social". Contudo, o elogio à política é feito em uma oração intercalada, que permite ser suprimida sem prejuízo de sentido na oração principal. Tal elemento aponta que as características positivas das cotas raciais não são o centro de sua argumentação, mas sim uma estratégia para gerar aproximação com o leitor a partir de uma imagem agradável de si. A meritocracia é evocada como lugar comum inquestionável e único meio de se manter a excelência universitária: é a "única forma, a única baliza" que, se desrespeitada, fere a função primordial da universidade. Já na última sentença, o locutor associa os alunos cotistas que fariam parte

\footnotetext{
${ }^{6}$ No original: "Whilst the view prevails that such conventions are unproblematic and simply 'common sense', I argue that confusion is so all pervasive a dimension of their experience as a group of "non-traditional' students in higher education that it points to an institutional practice of mystery".
} 
da comunidade universitária a uma perspectiva deficitária ao apontar que a troca do perfil dos estudantes custaria a excelência acadêmica. No contexto dos letramentos acadêmicos, entretanto, a necessidade de se reconhecer os diversos tipos de letramentos coloca em xeque a perspectiva meritocrática em que os discentes advindos de camadas populares são vistos a partir do conhecimento que lhes falta:

Ao tomar o conceito de letramento como a relação de uso que um indivíduo ou uma comunidade estabelece com a escrita, recuso o discurso da crise. Contrariamente ao que dizem muitos professores universitários em relação à escrita de seus alunos, entendo que esses estudantes são letrados e, muito provavelmente, não se engajaram ainda nas práticas letradas esperadas no contexto acadêmico (FIAD, 2011, p. 360).

Em contraposição aos argumentos contidos nos exemplos analisados, é possível verificar que as políticas afirmativas estão em curso no país há mais de 5 anos após a lei federal 12.711/2012 e há mais de 15 anos após as primeiras proposições de cotas nas universidades. Todo esse histórico, contudo, não caracterizou queda na qualidade de ensino das universidades e dados da UFMG apontam que alunos cotistas apresentam um desempenho no decorrer do curso que é igual ou superior ao de um aluno não cotista (TAKAHASHI; CAMINHAS, 2015). Nesse sentido, entendemos que as políticas de ação afirmativa de recorte racial devem ser interpeladas como meio de transformar a academia num espaço multicultural que negocia e amplia o conhecimento, resultando em novas formas de se perceber o mundo.

Nesse contexto, visualizamos novamente a correlação entre estudos de Lea e Street $(1998,2014)$ sobre os letramentos acadêmicos: estudiosos das relações étnico-raciais sempre apontaram para o fato de que o domínio de normas acadêmico-institucionais não passa por questões de ordem cognitiva ou individual, mas sim, por inclusão, dado que historicamente houve apagamento e silenciamento dos conhecimentos da população negra e indígena dos espaços de poder. Ademais, a argumentação baseada na meritocracia, em essência, apenas reiterou o racismo institucional sustentado pela nação desde o fim da escravidão. Nesse sentido, embora em momentos mais recentes os discursos que privilegiem a meritocracia e o suposto déficit de estudantes cotistas não sejam mais uma realidade constantemente presenciada, ainda é preciso direcionar esforços para a 
inserção epistemológica de povos tradicionalmente excluídos da academia. Por essa razão, faz-se urgente problematizar discursos referentes às relações étnico-raciais no contexto educacional, bem como as implicações de práticas mediadas pela escrita tanto para a manutenção quanto para o questionamento de relações de poder.

Por fim, entendemos que o modelo dos letramentos acadêmicos é de suma importância para promoção de uma universidade mais plural e inserida na comunidade da qual faz parte, ressignificando a noção de déficit presente no discurso da meritocracia para, então, considerar as diferentes práticas de letramento a que o discente cotista esteve submetido em sua trajetória. Para tanto, é necessário ter em mente que o cotidiano acadêmico é permeado por práticas institucionais específicas e não neutras; que devem ser explicitadas e não pressupostas como naturais, como se os estudantes fossem um todo homogêneo.

Mais ainda, é preciso considerar que uma perspectiva universitária que privilegie o modelo dos letramentos acadêmicos, notadamente no contexto das políticas de ações afirmativas, trata-se de algo relativamente novo no caso brasileiro, exigindo o questionamento de diversas bases em que a universidade há muito tempo tem se sustentado. Tal prática se caracteriza como iniciativa fundamental que proporcionará tanto uma revisão sobre o ensino de leitura e escrita na universidade, quanto uma possível abertura de novos campos de estudo e novas formas de compreensão sobre a noção de letramentos para os diferentes campos do saber.

\section{Considerações finais}

Promover uma breve reflexão sobre o contorno teórico que favoreceu o surgimento do modelo dos letramentos acadêmicos e correlacionar tal perspectiva ao contexto das atuais políticas de ação afirmativa de recorte racial foi o objetivo desse trabalho. Entendemos que a aplicação do modelo dos letramentos acadêmicos, que entende as noções de leitura e escrita como práticas sociais complexas e socialmente situadas, seja de urgente reconhecimento por parte das universidades. Isso porque, ao se apropriar de tal perspectiva, as instituições de ensino superior poderão melhor compreender os significados que a leitura e a escrita assumem em diferentes grupos sociais, tornando-se mais inclusiva, acolhedora e favorecendo o empoderamento de grupos minoritarizados. Por esse viés, os letramentos 
acadêmicos ganham importância não apenas quando associados a políticas de ingresso, mas também quando auxiliares de políticas de permanência universitária. Nesse sentido, com vistas a uma permanência satisfatória que garanta a efetivação acadêmica de estudantes cotistas, importa trazer a cultura e a identidade dos povos negros e indígenas para o centro das discussões, além da criação de bolsas acadêmicas que tenham como eixo os usos da linguagem nas diversas áreas do conhecimento. Por isso, entendemos com Fischer (2010, p.223) que,

As diferenças nos usos da língua não simbolizam deficiências, as quais precisam ser negadas. $O$ que conta como letramento na vida desses alunos precisa ser considerado, (re)visitado, em especial pelos professores, para que se questione, valorize, apoie, expanda o que é singular e/ou comum a esses sujeitos. Dessa forma, poder-se-á reagir ao discurso da crise ou do déficit do letramento.

Nesse sentido, é imperioso que a academia se aprofunde no modelo dos letramentos acadêmicos, buscando iniciativas que promovam diálogos na produção e reprodução do conhecimento, com práticas contextualizadas no que diz respeito às diversidades e à diferença (KLEIMAN, 1995). Por essa razão, as universidades contemporâneas trazem consigo o desafio de subverter lógicas colonialistas e de se fazerem mais plurais e inseridas no contexto comunitário do qual fazem parte.

\section{Referências}

BARTON, D. Literacy: an introduction to the ecology of written language. Cambridge: Brackwell, 1994.

BARTON, D.; HAMILTON, M. Local Literacies: reading and writing in one community. Londres: Routledge, 1998.

BRASIL. Congresso Nacional. Lei n ${ }^{\circ}$ 10.639, de 9 de janeiro de 2003. Altera a Lei no 9.394, de 20 de dezembro de 1996, que estabelece as diretrizes e bases da educação nacional, para incluir no currículo oficial da Rede de Ensino a obrigatoriedade da temática "História e Cultura Afro-Brasileira", e dá outras providências. Brasília, DF, 2003. Disponível em: < https://bit. ly/2RNgDC1>. Acesso em: 5 out. 2018. 
BRASIL. Congresso Nacional. Lei n 11.645, de 10 de março de 2008. Altera a Lei no 9.394, de 20 de dezembro de 1996, modificada pela Lei oㅜ 10.639, de 9 de janeiro de 2003, que estabelece as diretrizes e bases da educação nacional, para incluir no currículo oficial da rede de ensino a obrigatoriedade da temática "História e Cultura Afro-Brasileira e Indígena". Brasília, DF, 2008. Disponível em: < https://bit.ly/2kdW27D>. Acesso em: 5 out. 2018. BRASIL. Congresso Nacional. Lei no 12.711, de 29 de agosto de 2012. Dispõe sobre o ingresso nas universidades federais e nas instituições federais de ensino técnico de nível médio e dá outras providências. Brasília, DF, 2012. Disponível em: <https://bit.ly/1n0FDPs>. Acesso em: 6 out. 2018.

FIAD, R. S. A escrita na universidade. Revista da ABR ALIN, [S.l.], v. eletrônico, n. especial, 2. parte, 2011. Disponível em: <https://bit. ly/2VNTpL8>. Acesso em: 2 ago. 2018.

FIAD, R. S. Algumas considerações sobre os letramentos acadêmicos no contexto brasileiro. Pensares em Revista, São Gonçalo, n. 6, jan./jun., p. 23-34, 2015. Disponível em: <https://bit.ly/2y009xy>. Acesso em: 6 ago. 2018.

FISCHER. A. Os usos da língua na construção de sujeitos letrados: relações entre a esfera escolar e a acadêmica. Acta Scientiarum. Language and Culture, Maringá, v. 32, n. 2, p. 215-224, 2010. DOI: 10.4025/actascilangcult. v32i2.9257. Disponível em: < https://bit.ly/2FCqP9N>. Acesso em: 1 ago. 2018.

FRANCO, R. A. S. R.; CASTANHEIRA, M. L. Práticas de letramento acadêmico no Facebook. Ilha Desterro, Florianópolis, v. 69, n. 3, p. 1328, 2016. DOI: http://dx.doi.org/10.5007/2175-8026.2016v69n3p13. Disponível em: < https://bit.ly/2FuliTQ>. Acesso em: 18 nov. 2017.

GEE, J. P. Social Linguistics and Literacies: ideology in discourses. London: Taylor and Francis, 1996.

GOMES, N. L. Cultura negra e educação. Revista Brasileira de Educação, n. 23, p. 75-85, 2003. DOI: http://dx.doi.org/10.1590/S1413-24782003000200006. Disponível em: <https://bit.ly/2DbJyrq >. Acesso em: 8 dez. 2017.

KLEIMAN, A. (Org.). Os significados do letramento: uma nova perspectiva sobre a prática social da escrita. Campinas: Mercado das Letras, 1995. 
LARSON, J.; MARSH, J. Making literacy real: theories and practices for learning and teaching. London: Sage Publication, 2005. DOI: http://dx.doi. org/10.4135/9781446211953

LEA, M.; STREET, B. Student writing in higher education: an academic literacies approach. Studies in Higher Education, v. 23, n. 2, jun., p. 157-173, 1998. DOI: https://doi.org/10.1080/03075079812331380364. <>

LEA, M.; STREET, B. O modelo de "letramentos acadêmicos": teoria e aplicações. Filologia e Linguística Portuguesa, São Paulo, v. 16, n. 2, jul./ dez., p. 477-493, 2014. DOI: https://doi.org/10.11606/issn.2176-9419. v16i2p477-493. Disponível em: < https://bit.ly/2QQqsKL>. Acesso em: 17 nov. 2017.

LILLIS, T. "Whose Common Sense"? Essayist literacy and the institutional practice of mystery. In: JONES, C.; TURNER, J.; STREET, B. V. (Org.). Students writing in the university: cultural and epistemological issues. Amsterdam: John Benjamins, p. 127-140, 1999. DOI: https://doi.org/10.1075/ swll.8.13lil

LILLIS, T. Student Writing: access, regulation, desire. London: Routledge, 2001.

LILLIS, T.; SCOTT, M. Defining academic literacies research: issues of epistemology, ideology and strategy. Journal of Applied Linguistics, v. 4, p. 5-32, 2007. DOI: https://doi.org/10.1558/japl.v4i1.5. Disponível em: <https:// bit.ly/2VVhAr2>. Acesso em: 1 dez. 2017.

MARINHO, M. A escrita nas práticas de letramento acadêmico. Revista Brasileira de Linguística Aplicada, Belo Horizonte, v. 10, n. 2, p. 363-386, 2010. DOI: http://dx.doi.org/10.1590/S1984-63982010000200005. Disponível em: < https://bit.ly/2HbvyBX>. Acesso em: 17 nov. 2017.

SANTOS, K. R. C.; SOUZA, E. P. S. (Org.). SEPPIR: promovendo a igualdade racial para um Brasil sem racismo. Brasília, DF: Ministério das Mulheres, da Igualdade Racial, da Juventude e dos Direitos Humanos. 2016. Disponível em: <https://bit.ly/2HbVYne>. Acesso em: 1 dez. 2018.

SANTOS, J. S. As cotas raciais em uma publicaşão jornalística universitária: imagens das relações raciais brasileiras. 2016. Dissertação (Mestrado em Linguística) Faculdade de Letras, Universidade Federal de Minas Gerais, Belo Horizonte, 2016. 
SILVA, P. B. G. Negros na universidade e produção do conhecimento. In: SILVA, P. B. G.; SILVÉRIO, V. R. (Org.). Educação e ações afirmativas: entre a injustiça simbólica e a injustiça econômica. Brasília, DF: Instituto Nacional de Estudos e Pesquisas Educacionais Anísio Teixeira, 2003.

SITO, L. R. S. Escritas afirmativas: estratégias criativas para subverter a colonialidade em trajetórias de letramento acadêmico. 2016. Tese (Doutorado em Linguística Aplicada) - Instituto de Estudos da Linguagem, Universidade Estadual de Campinas, Campinas, 2016.

SOARES, M. Letramento: como definir, como avaliar, como medir. In: . Letramento: um tema em três gêneros. Belo Horizonte: Autêntica, 1998. p. 62-125.

SOUZA, A. L. S. Letramentos de reexistência: culturas e identidade no movimento hip hop. 2009. Tese (Doutorado em Linguística Aplicada) Instituto de Estudos da Linguagem, Universidade Estadual de Campinas, Campinas, 2009.

STREET, B. Literacy in theory and practice. Cambridge: Cambridge University Press, 1984.

STREET, B. What's 'new' in new literacy studies? Critical approaches to literacy in theory and practice. Current Issues in Comparative Education, Columbia, v. 5, n. 2, p. 77-92, maio 2003. Disponível em: https://bit. ly/2sw8CTy. Acesso em: 30 jul. 2018.

STREET, B. Perspectivas interculturais sobre o letramento. Tradução Marcos Bagno. Filologia e Linguística Portuguesa, São Paulo, n. 8, p. 465-488, 2006. DOI: https://doi.org/10.11606/issn.2176-9419.v0i8p465-488. Disponível em: <https://bit.ly/2VSckVc>. Acesso em: 2 dez. 2017.

STREET, B. Dimensões “escondidas” na escrita de artigos acadêmicos. Perspectiva, Florianópolis, v. 28, n. 2, p. 541-567, jul./dez., 2010. DOI: 10.5007/2175-795X.2010v28n2p541. Disponível em: <https://bit. ly/2ANOwZM>. Acesso em: 22 de jun. 2017.

STREET, B.; CASTANHEIRA, M. L. Práticas e eventos de letramento. In: FRADE, I. C. A. S.; COSTA VAL, M. G.; BREGUNCI, M. G. C. (Org.). 
Glossário Ceale: termos de alfabetização, leitura e escrita para educadores. Belo Horizonte: UFMG, 2014.

TAKAHASHI, R.; CAMINHAS, W. Mudanças no ensino de graduação da UFMG: análise e perspectivas. Belo Horizonte: UFMG, 2016. Disponível em: <https://bit.ly/2swjYqF>. Acesso em: 30 jul. 2018.

UNIVERSIDADE FEDERAL DE MINAS GERAIS. Boletim, Belo Horizonte, (edições on-line), v. 31, n. 1482, 2005. Disponível em: < https:// bit.ly/2QR5XO4>. Acesso em: 16 nov. 2017.

UNIVERSIDADE FEDERAL DE MINAS GERAIS. Boletim, Belo Horizonte, (edições on-line), v. 32, n. 1535, 2006. Disponível em: <https:// bit.ly/2QR5XO4>. Acesso em: 16 nov. 2017.

ZAVALA, V. Quem está dizendo isso? Letramento acadêmico, identidade e poder na educação. In: VÓVIO, C.; SITO, L.; DE GRANDE, P. (Org.). Letramentos: rupturas, deslocamentos e repercussões de pesquisas em linguística aplicada. Campinas: Mercado de Letras, p.71-95, 2010. 